\title{
The importance and usefulness of terminology and nomenclature for Cytopathology
}

Luiz M. Collaço

Nomenclature and terminologies for Cytopathology have intended to group the diseases into categories, reduce interobserver variability, and improve diagnostic reproducibility and patient care. They should contain relevant information that can be understood by clinicians/surgeons and reflect current concepts on certain pathological processes. Currently, they are worked by interdisciplinary groups seeking answer specific objectives and are associated with well-defined conducts. The cervical cytology had its first systematization with the classes of Papanicolaou, which due to the difficulty of correlating with Histopathology, was gradually abandoned. Other ways to write the reports followed it, as the World Health Organization (WHO) classification - categorized the lesions in dysplasias -, the Richart's - intraepithelial neoplasia - and finally the Bethesda (nomenclature) System, obtained in a consensus meeting and added important topics, such as the assessment of sample satisfactoriness, atypia of undetermined significance, and the binary division of squamous lesions in low and high grade ${ }^{(2,5)}$.

The nomenclature is undergoing changes and improvements over the years following the modification of the pathogenesis of cervical lesions and closely associated with clinical procedures. Its latest version, this year, 2014, was under consultation via electronic site between March and June, and is about to be launched through a new book that will include a chapter on risk assessment for cervical cancer screening.

The fine needle aspiration of the thyroid also received their classification by the Bethesda System for Reporting Thyroid Cytology. The nomenclature has six categories well-connected to the risk of malignancy and clinical management/surgical associated, namely: inconclusive, benign, atypia of undetermined significance, follicular neoplasm, suspicious for malignancy, and malignant. Among them, the atypia of undetermined significance is the most controversial because of heterogeneity in relation to diagnostic characterization and anatomopathological correlation ${ }^{(3)}$. The nomenclature got rapid dissemination and has achieved a wide participation among clinicians, surgeons and pathologists; they are currently used and extremely recommended.

The latest attempt to standardization concerns the urine cytology. The International Academy of Cytology (IAC), at its 2013 Congress in Paris, began the works aiming at providing a terminology for this area. Later, they obtained the support of the American Society of Cytopathology and a working group was formed to format a nomenclature. A website was created, there different chapters related to the terminology proposal were discussed. Formatting by the year 2014, recommends that the urine Cytology reports should provide information about the satisfactoriness of the sample and the result expressed in one of the following categories: negative for high-grade carcinoma cells, atypical urothelial cells (including low-grade urothelial carcinoma), suspicious for high grade urothelial carcinoma cells, high-grade urothelial carcinoma, other malignant neoplasms (primary / metastatic) ${ }^{(1)}$. Information on the development of the nomenclature may be accompanied by the electronic addresses http://www.cytology-iac.org ${ }^{(1)}$ and http://www.cytopathology.org ${ }^{(6)}$. By 2016 a book containing the nomenclature and interpretation will be launch, according to the same guidelines of that one edited for thyroid and cervical cytology.

Pathologist/cytopathologist; master and PhD in Medicine; professor of Pathologic Anatomy at Faculdade Evangélica do Paraná, and Universidade Federal do Paraná; membership of the International Academy of Cytology. 
Another area that has received attention in recent years is the pancreaticobiliary cytology. The increase in guided fine needle aspiration, transabdominal or endoscopic, has allowed access to lesions of different diameters with high accuracy. Symposia, algorithms and guidelines have been published for the purpose of familiarizing pathologists with the cytology of this area, in addition to correlate it with the most appropriate conducts for each case. A multimodal approach is advocated, including clinical and radiological information, as well as auxiliary tests, when indicated, as the measure of carcinoembryonic antigen (CEA), amylase, or molecular testing to check for K-RAS mutations. Currently, there is a nomenclature proposed by the Papanicolaou Society of Cytopathology (PSC) consisted of six categories: nondiagnosis, negative, atypical, neoplasia (benign/other - including the mucinous cystic neoplasm, neuroendocrine tumors, solid pseudopapillary tumor/neoplasm, etc.) suspect, positive/malignant ${ }^{(4)}$.

The straightforward communication through a universal language has been increasingly encouraged and applied in the medical field. Therefore, the nomenclature/terminology recommended by international organizations are showing increasing acceptance and application, also in Cytopathology, and should be discussed, disseminated and used in context so that they can improve the understanding of what is intended to be expressed from the cytological findings and impact positively the patient care. As presently done, we still notice a gap for breast cytology, which may be one of the following topics to have its standards established.

\section{REFERENCES}

1. ASC. American Society of Cytopathology. Available at: <http://www.cytopathology.org >. Access: December. 2014.

2. GAMBONI, M.; MIZIARA, F. E. Manual de citopatologia diagnóstica. 1. ed. São Paulo, 2013.

3. J0, V. Y. et al. Malignancy risk for fine-needle aspiration of thyroid lesions according to the bethesda system for reporting thyroid cytopathology. Am J Clin Pathol, v. 134, p. 450-6, 2010.

4. PITMAN, M. B.; LAYFIELD, J. L. Guidelines for pancreaticobiliary cytology from the Papanicolaou Society of Cytopathology: a review. Cancer (Cancer Cytopathol), v. 122, n. 6, p. 399-411, 2014.

5. SOLOMON, D.; NAYAR, R. The Bethesda system for reporting cervical cytology. 2. ed. New York: Springer, 2004.

6. THE International Academy of Cytology. Available at: <http://www.recantodasletras.com.br/e-livros/2172890>. Access: 9 October. 2009. 